\title{
Minimally invasive management of 14-16-week abdominal ectopic with hemoperitoneum: an emergency laparoscopic procedure
}

\author{
Mohammed Rizk ${ }^{1}$. Haitham Salem ${ }^{2}$
}

Received: 19 May 2015 / Accepted: 6 August 2015 / Published online: 20 August 2015

(C) Springer-Verlag Berlin Heidelberg 2015

\begin{abstract}
Since the first laparoscopic cholecystectomy on a pregnant lady in 1991, a plethora of articles and case studies have been published addressing laparoscopy and their role in pregnancy. The Royal College of Obstetricians and Gynecologists Green-top Guidelines recommends laparoscopic surgery as the preferred approach in early ectopic tubal pregnancies. Laparoscopic versus laparotomy management of abdominal ectopic is a traumatic experience both on physical and emotional levels. The case study was a 36-year-old gravida 2 para 0 patient, previously normal pregnant lady, in which the follow-up ultrasound revealed moderate hemoperitoneum at 14-16 weeks of gestation. Upon urgent diagnostic laparoscopy, massive hemoperitoneum was detected despite no clinical signs of hemodynamic instability. Uterus was found to be within the normal measurements consistent with the nonpregnant state. Multiple myomas were clearly seen in the uterine wall. A fetus of 14-16 weeks was detected attached to the colon during formal laparoscopic pelvic and abdominal exploration for ectopic pregnancy. Operative laparoscopy for abdominal ectopic in skillful hands can be considered a feasible management technique carrying all the advantages of a minimally invasive procedure.
\end{abstract}

Keywords Laparoscopy $\cdot$ Ectopic pregnancy $\cdot$ Minimally invasive surgery

Mohammed Rizk

mohammed.rizk@gmail.com

1 Obstetrics \& Gynecology Department, Ain Shams University, Cairo, Egypt

2 Surgery Department, Cairo University, Cairo, Egypt

\section{Introduction}

For women in the reproductive age, ectopic pregnancy is one of the most serious conditions to be considered in differential diagnosis of abdominal pain. First described by Wendeler et al. in 1895, Eccyesis or ectopic pregnancy is characterized by implantation of the fertilized ovum in a position other than the uterine cavity [1]. It occurs by a rate of $1-2 \%$ of all pregnancies in developed countries [2]. Eccyesis is generally classified into tubal and nontubal pregnancies. More than $90 \%$ of the abnormal implantation occurs in the Fallopian tube (tubal pregnancies), while the rest (nontubal) might occur at the ovary, cervix, or intra-abdominal [3-5].

In a medical field with extensive scientific advances, ectopic pregnancy remains a major cause of death, particularly during the first trimester (Varma and Gupta [6]). Risk factors include previous ectopic, PID, smoking, multi-parity, previous abortion, tubal surgery, assisted reproductive technology, extremes of age, IUD, and DES exposure in utero [7]. Nitric oxide and low socioeconomic status were also reported as potential risks $[8,9]$. However, in up to $50 \%$ of the cases, no risk factors can be identified [10].

The broad spectrum of clinical manifestations with ectopic pregnancy complicates the diagnosis, as they vary from asymptomatic cases to acute abdomen and hemodynamic shock. Most of the cases were initially undiagnosed until complicated with massive hemorrhage or turned into a lifethreatening condition. A high index of suspicion with close follow-up is mandatory for early detection of an ectopic pregnancy (Crochet at al. [11]).

Management generally includes medical or surgical methods; both are effective, but the selection depends on clinical situation, localization of ectopic pregnancy, and diagnostic tools. The first successful surgery for an ectopic pregnancy was performed by Robert Lawson Tait in 1883 [12]. Recently, 


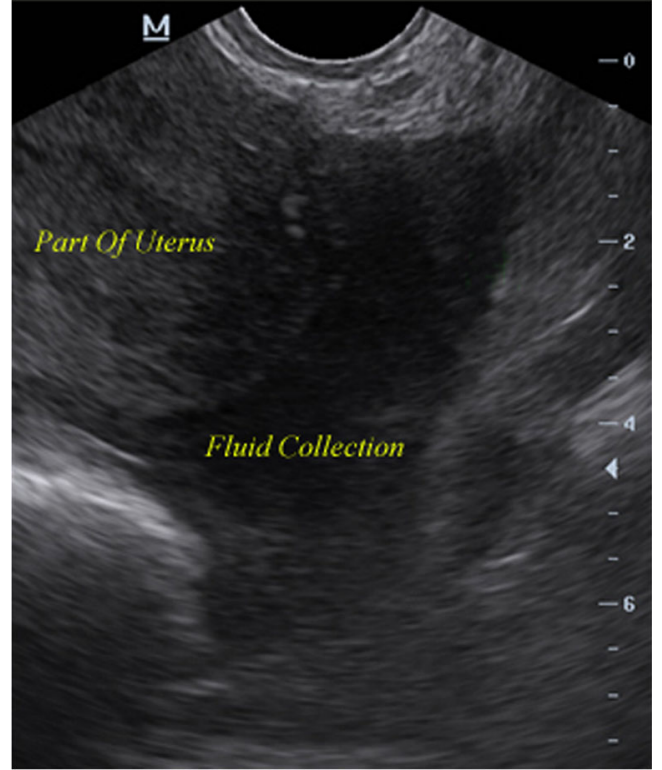

Fig. 1 Ultrasound image in the emergency setting showing the fluid collection in the abdomen and pelvis, with a nongravid uterus

Laparoscopy has experienced numerous changes and developments, replacing to a great extent the traditional laparotomy procedure [13]. Laparoscopic approach has many benefits; it yields less postoperative pain, shorter hospital stay, faster recovery, and better aesthetic results $[14,15]$.

Although laparoscopy is not indicated for all clinical scenarios, it has become the gold standard for numerous obstetric and gynecological situations [16]. Moreover, unusual types of ectopic are being recently managed with laparoscopic surgery [17].

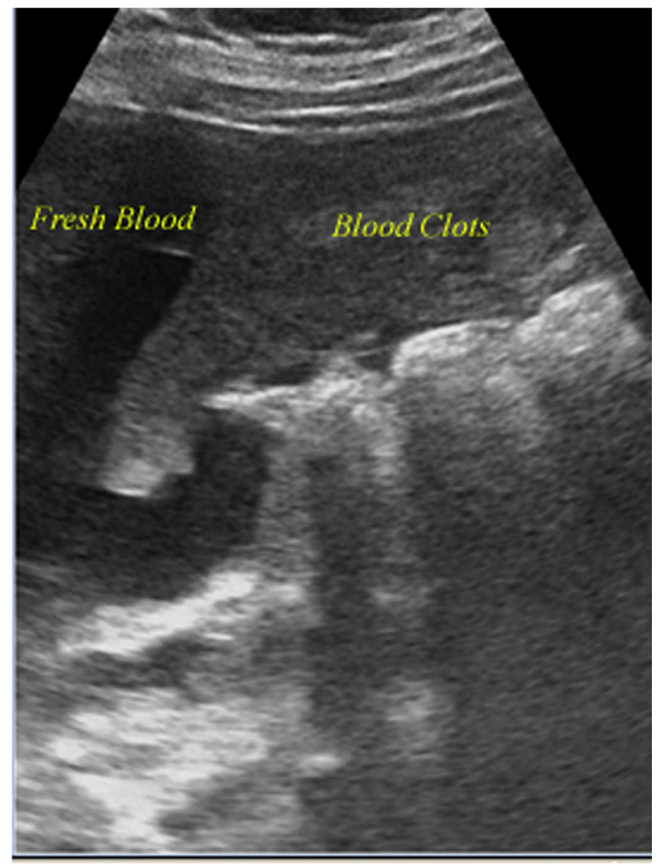

Fig. 2 Ultrasound image showing blood clots and fresh bleeding in the abdomen and pelvis

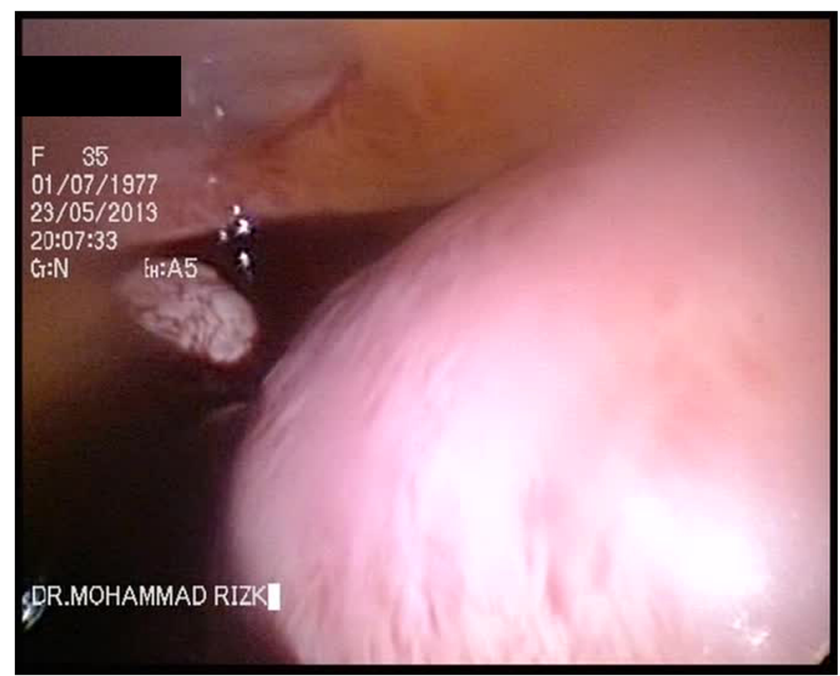

Fig. 3 First look by the laparoscopy camera showing the intra-abdominal collection, with no apparent adnexa

\section{Case}

The patient was a 36-year-old Middle Eastern Saudi female, gravida 2 para 0 at 14 weeks and 5 days gestational age based on her last menstrual period. She presented to the emergency department with cramping lower abdominal pain. She has a history of right salpingectomy for previous ectopic pregnancy management. The patient rated her pain as 8 on a severity scale of 10. Physical examination revealed supra-pubic and right lower quadrant tenderness, with no signs of acute peritonitis. She was hemodynamically stable; blood pressure $135 / 83 \mathrm{mmHg}$, hemoglobin $10.2 \mathrm{mg} / \mathrm{dl}$, and positive beta hCG. Transvaginal ultrasound revealed no evidence of an intrauterine pregnancy but did show moderate to large amount of complex collection of fluid in the anterior and posterior cul-de-sacs. An ill-defined mass was also noticed; extending slightly to the right of midline (Figs. 1 and 2). These findings were concerning for a ruptured ectopic

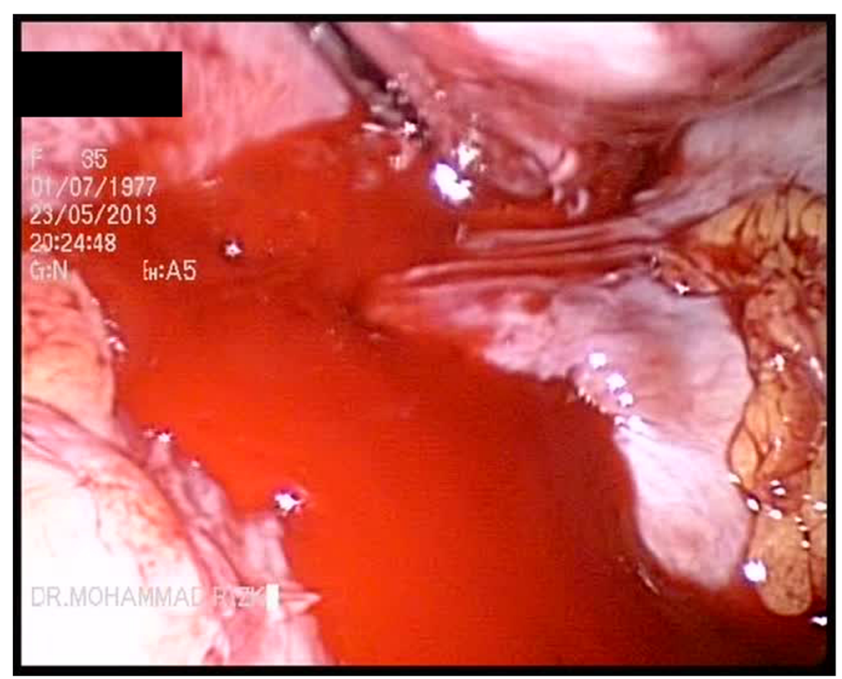

Fig. 4 Exploration showing the intra-abdominal collection 


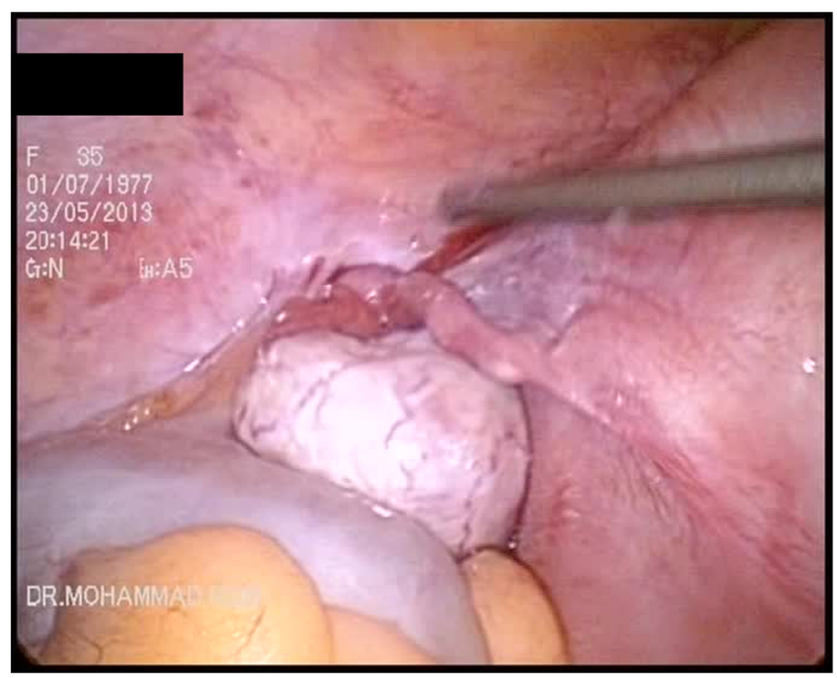

Fig. 5 Ovary and tube after clearing the intra-abdominal collection

pregnancy. In light of the patient's symptoms and clinical data, the patient was taken to the operating room for a diagnostic laparoscopy. On inspection, large clots of blood were noticed in the pelvis with active oozing (Figs. 3 and 4). The uterus appeared bulky and malformed by multiple myomas. The left tube and ovary appeared within normal measures (Fig. 5), while the right tube was not present, and the right ovary was detected after aspiration and removal of omental adhesions. An intact corpus luteum was noticed on the left ovary. However, on further abdominal exploration, omental adhesions were noticed near the right ovary (Fig. 6). On inspection, the omentum was found to have a fetus about 14 to 16 weeks (Figs. 7 and 8). At this time, our presumptive diagnosis was an abdominal pregnancy. Adhesiolysis was done with removal of the fetus within an Endobag followed by separation of the omental-placental attachments with partial omentectomy, and then proper hemostasis was achieved. The patient did well postoperatively and was discharged home on postoperative day 1 . The patient was given methotrexate in the postoperative period.

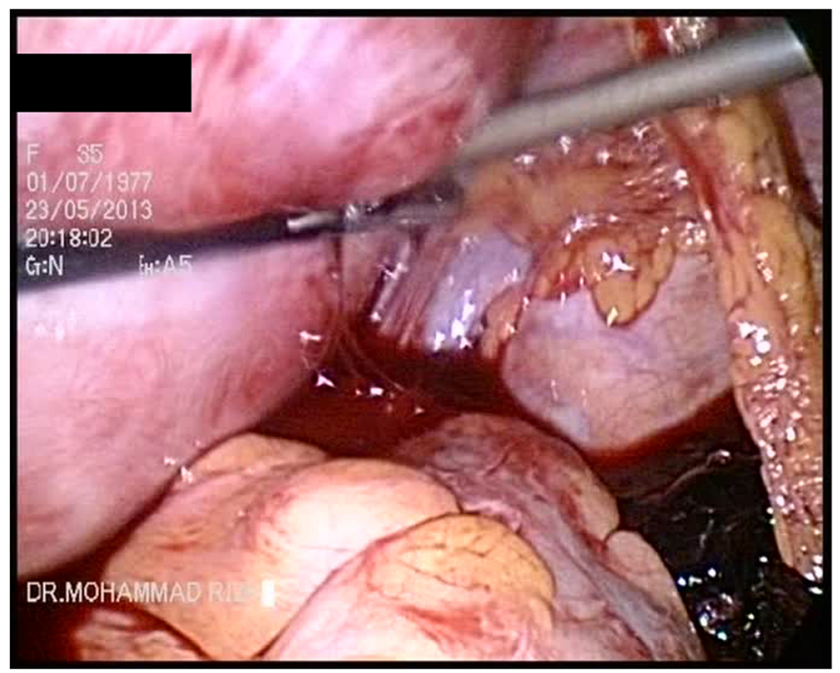

Fig. 6 Adhesiolysis for further exploration

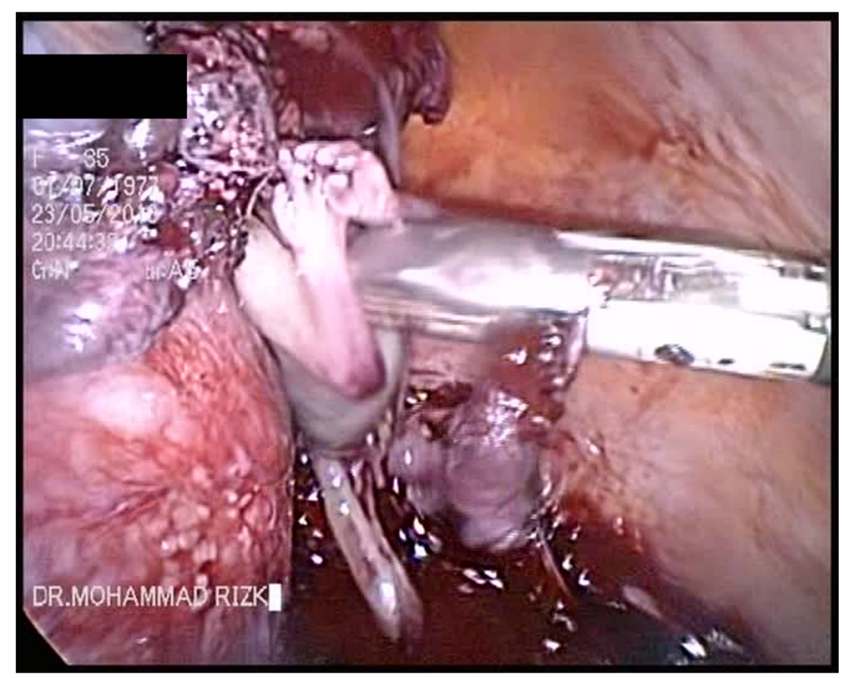

Fig. 7 Peritoneal pregnancy was detected with fetus seen

\section{Discussion}

With an incidence of 1 to 10,000 live births, primary abdominal pregnancy is considered an extremely rare form of ectopic pregnancy $[18,19]$. Criteria for omental pregnancy were described in 1942 by Studdiford: normal bilateral fallopian tubes and ovaries, absence of utero-peritoneal fistula, and presence of a pregnancy related to the peritoneal surface exclusively. Our patient here met the diagnostic criteria of Studdiford. Only few reported cases have been treated using laparoscopy in literature [20,21].

In 1997, a case of primary omental pregnancy diagnosed with laparoscopy at 6-weeks gestational age was described, where a hemorrhagic mass was noticed to be adherent to the omentum close to the left ovary [22]. It was an answer to a previous doubt about the existence of a true omental pregnancy [23]. In 2004, laparoscopic treatment of an abdominal pregnancy was reported, where the gestational sac was noticed in the Douglas pouch [24].

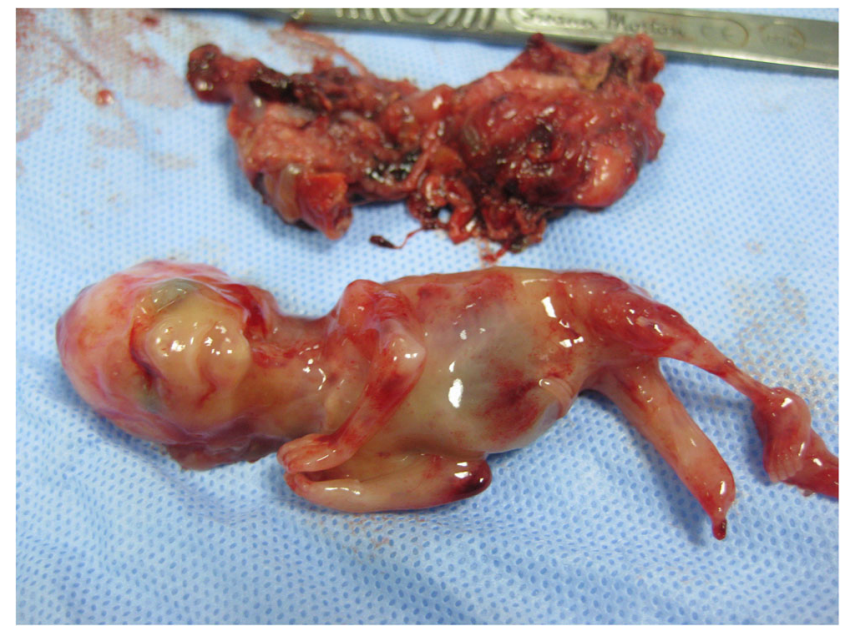

Fig. 8 Fourteen- to 16-week fetus after extraction 
Many other reports in the literature describing a hemorrhagic mass with blood clots appeared to be a consistent finding [25, 26]. Hemorrhage is a key factor requiring conversion from laparoscopy to laparotomy [27]. Laparotomy is recommended in most cases due to the risk of significant hemorrhage from the implantation site. Thus, the main stream in literature regarding ectopic pregnancy treatment is usually laparotomy, but with the introduction of laparoscopic surgery, it is now possible to manage these cases with minimally invasive techniques. There are multiple successful case reports of laparoscopic resection of ectopic pregnancies $[28,29]$. Massive hemoperitoneum is not an absolute contraindication for laparoscopic management of ectopic pregnancy anymore [16].

Our patient was hemodynamically stable, and hence, we were able to perform laparoscopy without any complications. Although the advanced age of the abdominal pregnancy (1416 weeks) is not usually treated with a laparoscopic approach, we proved that minimally invasive technique could be a feasible way of management.

\section{Conclusion}

Operative laparoscopy for abdominal ectopic in skillful hands can be considered a feasible management technique carrying all the advantages of a minimally invasive procedure.

Conflict of interests The authors declare that there is no conflict of interests regarding the publication of this paper.

Compliance with ethical standards All procedures performed in this report were in accordance with the ethical standards of the institutional and/or national research committee and with the Helsinki declaration and its later amendments. Written informed consent was obtained from the patient for publication of this case report and any accompanying images.

\section{References}

1. Villegas E, González-Mesa E, Benítez MJ, Luna S, Gómez C, Marsac A, Jiménez J (2014) Tubal ectopic pregnancy two years after laparoscopic supracervical hysterectomy. BMC Womens Health 14:69. doi:10.1186/1472-6874-14-69

2. Kirk E, Bottomley C, Bourne T (2014) Diagnosing ectopic pregnancy and current concepts in the management of pregnancy of unknown location. Hum Reprod Update20(2):250-61

3. Creanga AA, Shapiro-Mendoza CK, Bish CL, Zane S, Berg CJ, Callaghan WM (2011) Trends in ectopic pregnancy mortality in the United States: 1980-2007. Obstet Gynecol 117(4):837-43

4. Kopani F, Rrugia A, Manoku N (2010) Ectopic pregnancy comparison of different treatments. J Prenat Med 4(2):30-4

5. Cecchino GN, AraujoJúnior E, Elito Júnior J (2014) Methotrexate for ectopic pregnancy: when and how. Arch Gynecol Obstet 290(3): $417-23$

6. Varma R, Gupta J (2009) Tubal ectopic pregnancy. BMJ Clin Evid. Apr 20;2009. pii: 1406
7. Menon S, Sammel M, Vichnin M, Barnhart KT (2007) Risk factors for ectopic pregnancy: a comparison between adults and adolescent women. J PediatrAdolesc Gynecol 20:181-185

8. Al-Azemi M, Refaat B, Amer S, Ola B, Chapman N, Ledger W (2009) "The expression of inducible nitric oxide synthase in the human fallopian tube during the menstrual cycle and in ectopic pregnancy". FertilSteril 94(3):833-840

9. Yuk JS, Kim YJ, Hur JY, Shin JH (2013) Association between socioeconomic status and ectopic pregnancy rate in the Republic of Korea. Int J Gynaecol Obstet 122(2):104-7

10. Majhi AK, Roy N, Karmakar KS, Banerjee PK (2007) Ectopic pregnancy an analysis of 180 cases. J Indian Med Assoc 105(6): $308,310,312$

11. Crochet JR, Bastian LA, Chireau MV (2013) Does this woman have an ectopic pregnancy?: the rational clinical examination systematic review. JAMA 309(16):1722-9

12. Saranovic M, Vasiljevic M, Prorocic M, Macut ND, Filipovic T (2014) Ectopic pregnancy and laparoscopy. Clin Exp Obstet Gynecol 41(3):276-9

13. Olweny EO, Best SL, Tracy CR, Cadeddu JA (2012) Comparison of outcomes of laparoscopic versus open appendectomy in adults: data from the Nationwide Inpatient Sample (NIS), 2006-2008. Arch Esp Urol 65(3):434-43

14. Khan KS, Wojdyla D, Say L, Gülmezoglu AM, Van Look PF (2006) WHO analysis of causes of maternal death: a systematic review. Lancet 367:1066-1076

15. Wang YL, Weng SS, Huang WC, Su TH (2014) Laparoscopic management of ectopic pregnancies in unusual locations Taiwan. J Obstet Gynecol 53(4):466-70. doi:10.1016/j.tjog.2014.01.004

16. Chaudhary P, Manchanda R, Patil VN (2013) Retrospective study on laparoscopic management of ectopic pregnancy. J ObstetGynaecol India 63(3):173-6. doi:10.1007/s13224-0120304-z. Epub 2012 Nov 10

17. Yan CM (2010) Laparoscopic management of three rare types of ectopic pregnancy. Hong Kong Med J 16(2):132-6

18. Cunningham G, Leveno KJ, Bloom SL, Hauth JC, Rouse DJ, Sponge CY (2010) "Ectopic pregnancy,". In: Williams Obstetrics, 23rd edn. McGraw-Hill, New York, NY, USA, pp 238-256

19. Atrash HK, Friede A, Hogue CJR (1987) Abdominal pregnancyin the United States: frequency and maternal mortality. Obstet Gynecol 69(3 Pt 1):333-7

20. Studdiford WE (1942) Primary peritoneal pregnancy. Am J Obstet Gynecol 44(3):487-491

21. Watrowski R, Lange A, Möckel J (2015) Primary omental pregnancy with secondary implantation into posterior cul-de-sac: laparoscopic treatment using hemostatic matrix. J Minim Invasive Gynecol 22(3):501-3. doi:10.1016/j.jmig.2014.06.008, Epub 2014 Jun 25

22. Weeks AD, Aagaard J, Bromham D (1997) Laparoscopic management of an abdominal pregnancy. Gynaecol Endosc 6(4):249-250

23. Berghella V, Wolf SC (1996) Does primary omental pregnancy exist? Gynecol Obstet Invest 42(2):133-6

24. Gerli D, Rossetti G, Baiocchi G, Clerici V, Unfer G, Di Renzo C (2004) Early ultrasonographic diagnosis and laparoscopic treatment of abdominal pregnancy. Eur J Obstet Gynecol Reprod Biol 113(1): 103-105

25. Morita Y, Tsutsumi O, Kuramochi K, Momoeda M, Yoshikawa H, Taketani Y (1996) Case report: successful laparoscopic management of primary abdominal pregnancy,”. Hum Reprod 11(11): 2546-2547

26. Tsudo T, Harada T, Yoshioka H, Terakawa N (1997) Laparoscopic management of early primary abdominal pregnancy. Obstet Gynecol 90(4):687-688

27. Walid MS, Heaton RL (2010) Diagnosis and laparoscopic treatment of cornual ectopic pregnancy. Ger Med Sci 27:8 
28. Eom JM, Choi JS, Ko JH, Lee JH, Park SH, Hong JH, Hur CY (2013) Surgical and obstetric outcomes of laparoscopic management for women with heterotopic pregnancy. J ObstetGynaecol Res 39(12):1580-6. doi:10.1111/jog.12106
29. MacRae R, Olowu O, Rizzuto MI, Odejinmi F (2009) Diagnosis and laparoscopic management of 11 consecutive cases of cornual ectopic pregnancy. Arch Gynecol Obstet 280(1):59-64 